\title{
The Effect of Hydraulic-Natural Fracture Networks on the Waterflooding Development in a Multilayer Tight Reservoir: Case Study
}

\author{
Gang Hui, ${ }^{1}$ Shengnan Chen $\mathbb{D}^{1},{ }^{1}$ Youjing Wang, ${ }^{2}$ and Fei Gu ${ }^{2}$ \\ ${ }^{1}$ Department of Chemical and Petroleum Engineering, University of Calgary, Calgary, Canada T2N1N4 \\ ${ }^{2}$ Research Institute of Petroleum Exploration \& Development, Beijing 100083, China \\ Correspondence should be addressed to Shengnan Chen; snchen@ucalgary.ca
}

Received 22 October 2020; Revised 12 November 2020; Accepted 18 December 2020; Published 21 January 2021

Academic Editor: Richeng Liu

Copyright ( $) 2021$ Gang Hui et al. This is an open access article distributed under the Creative Commons Attribution License, which permits unrestricted use, distribution, and reproduction in any medium, provided the original work is properly cited.

\begin{abstract}
An integrated hydraulic fracturing followed by waterflooding was conducted in a heterogeneous sandstone formation in the Northern Shanxi Slop of Ordos Basin in Western China. Water breakthrough quickly occurred, and the underlying mechanism of water breakthrough has not been well understood. Such mechanism needs to be investigated comprehensively from the spatial connectivity of multilayer sand bodies and characterization of hydraulic-natural fracture networks. Here, an integrated approach is proposed to tap the remaining oil in the individual sand layer during the late-stage development of tight sandstone reservoirs. A case study is utilized to demonstrate the applicability of the integrated method. It is found that the six sand layers could be further divided within the target oil layers. These sand layers have a variety of physical and mechanical properties, leading to the asymmetric spatial distribution of hydraulic fractures after performing the integrated fracturing of whole oil layers. The spatial difference of sand bodies conforms to the features of the multiperiod superimposed channel in the sedimentary environment of fan delta front. The natural fractures were generated from the tectonic movement in the Mesozoic period with a dominant orientation of approximately $\mathrm{NE} 67^{\circ}$. The asymmetric hydraulic fractures propagated and connected with the preexisting natural fractures, forming the intricate natural-hydraulic fracture networks. The water breakthrough pattern in each sand layer is primarily ascribed to the spatial distribution of the hydraulic-natural fracture networks and sedimentary microfacies. The refracturing operations based on the remaining oil distribution in sand layers are proven to be effective in further developing the formation. The average oil production of related wells increased from $0.61 \mathrm{t} / \mathrm{d}$ to $2.18 \mathrm{t} / \mathrm{d}$. This practical development strategy provides insights for further development of likewise heterogeneous tight sandstone reservoirs.
\end{abstract}

\section{Introduction}

In Western China, along with the long-term water injection development, the oil production within pay zones is uneven in the naturally fractured tight sandstone reservoirs and usually accompanied by the increasing water cut $[1,2]$. The fracture-induced water breakthrough is frequently observed shortly after the integrated fracturing operations targeting the whole oil layers ([3,4]; Van et al., 2018). The trigger mechanisms of such fracture-induced water breakthrough have not been well investigated, especially in consideration with the spatial connectivity of multistage sand bodies and the intricate hydraulic-natural fracture networks after the integrated fracturing operations $[1-3,5]$. Thus, it is necessary to conduct the comprehensive study to characterize the hydraulic-natural fracture networks based on the multistage sand layers subdivision in these reservoirs. The improve understanding of individual layer-based fracture network could help propose proper strategy to tap the remaining oil in the late stage development of tight sandstone reservoir.

The hydraulic fracturing technology has been widely utilized in the development of the tight sandstone reservoirs. In 1947, the hydraulic fracturing was first performed in field tests in Kansas, USA [6]. Fast et al. [7] proposed the largescale hydraulic fracturing technology in the ultralow permeability Wattenberg gas field. However, although the large- 
scale hydraulic fracturing is effective in enhancing the oil recovery of some reservoirs, it is not practical in some low permeability reservoirs [4]. Rahim et al. [8] used the finite difference method to simulate the impact of operational and geomechanical parameters on hydraulic fracturing in the layered reservoirs. The results suggested that if the interlayers developed in the pay zones, it was necessary to perform fracturing stimulation for each single oil layer, as the interlayers may function as the barriers to restrain the vertical propagation of hydraulic fractures. Abdideh et al. [9] argued that the favourable oil layer for hydraulic fracturing should be optimized based on the comprehensive study of rock mechanics, in situ stress field, proper density of drilling fluid, and various stress changes caused by fracturing treatments. Wen et al. [10] proposed the integrated fracturing theory for low porosity-low permeability reservoirs, which improved the development effect of integrated hydraulic fracturing in these reservoirs.

However, although the integrated fracturing may be suitable for the early stage of oilfield development, it may not be practical in the middle-late stage oilfield development $[4,5]$. Instead, the single sand body-based fracturing operations are required in the late stage $[11,12]$. Wang et al. [11] studied the factors that affected the refracturing effect in the lowpermeability oilfields. The heterogeneity within the oil layers plays an essential role on the stimulation effect of refracturing in low permeability reservoirs. Weng et al. [12] conducted in-depth research on the well and layer selection in the WY Oilfield. The potential natural fractures may pose the significant role on the effect of refracturing in the low permeability reservoirs. Thus, the spatial connectivity of multistage superimposed sand bodies, combined with complex hydraulic-natural fracture networks should be investigated comprehensively to tap the remaining oil effectively via refracturing the individual sand layer.

An integrated approach is proposed to tap the remaining oil in each sand layer during the late-stage development of tight sandstone reservoirs. A case study is utilized to demonstrate the applicability of the integrated method. Based on the division of sand layers and analysis of sedimentary facies, the hydraulic-natural fracture networks in each sand layer are determined by combining the inferred natural fractures with simulated hydraulic fractures. The refracturing measures are then conducted to tap the remaining oil within in the individual sand layer.

\section{Materials and Methods}

Figure 1 shows an integrated approach used to tap the remaining oil in the heterogeneous sand layers in the late stage development of tight sandstone reservoirs. Specifically, the multiscale field database is first established by collecting outcrops and core observation, well logging, production, and monitoring data. The sand layer division and sedimentary facies analysis are then conducted by comprehensively analysing the multiscale data. Next, the single sand body-based fracture network is established by combining the inferred natural fractures with simulated hydraulic fractures. A 3D single sand body-based geological model is finally built up. The proper development strategy is proposed accordingly to tap the remaining oil in the individual sand layer. The specific procedures for this integrated approach are the following.

2.1. Stratigraphic Subdivision and Sedimentology Analysis. The availability of outcrops and core data provides a good opportunity for further dividing the possible sand layers within oil layers. The relationship between the core observation results and well logging features is first investigated. The muddy or calcareous interlayers are then distinguished from the sand bodies, which mark the boundary between two adjacent single layers [13]. The sedimentary microfacies at the well sites are interpreted from the core observation and well logging response in each single layer [14]. Based on the well-established sedimentary pattern, the microfacies between the wells are finally determined to characterize the spatial connectivity of each individual sand layer. Moreover, this connectivity could also be corroborated by the related response between the injection wells and production wells.

\subsection{Determination of Hydraulic-Natural Fracture Networks.}

The generation of natural fractures is primarily attributed to the regional tectonic movement. The spatial distribution of natural fractures could be determined by the fractureinduced water breakthrough and tracer test. The natural fracture at the well site is identified by the characteristic image logging and well logging response. The natural fracture properties (i.e., strike, dip, and filling state) could be obtained from the imaging logging analysis of coring wells [15]. The propagation of hydraulic fractures is simulated based on the rock mechanical properties and real-time treatment data. The mechanical properties (i.e., Poisson's ratio and Young's modulus) of rocks are estimated first from the velocity logging data. The real-time treatment data of stimulated wells are then utilized to determine the geometry of hydraulic fractures by history-matching the net operational pressure [16]. Finally, the hydraulic-natural fracture networks are built up to investigate their effect on the waterflooding in the area.

2.3. Tapping the Remaining Oil of Individual Sand Layer. The $3 \mathrm{D}$ single sand body-based geological model is established by integrating results from the sand layer subdivision, microfacies analysis, and fracture network realization. The spatial distribution of the remaining oil is then determined within the single sand layer (Lin et al., 2018). Finally, the corresponding measures of reperforation and refracturing could be conducted to further tap the remaining oil within the corresponding individual sand layer.

\section{Results and Discussion}

3.1. Field Background. A case study is utilized to demonstrate the applicability of the aforementioned integrated method. The study region is located in the Northern Shanxi Slop of Ordos Basin in Western China (Figure 2). The main production layers are the $\mathrm{C}^{1}$ oil layer group of Yanchang Formation in the Upper Triassic System of the Mesozoic period. Under the sedimentary setting of fan delta facies, the multistage sand bodies in the target reservoir display different superposition patterns and internal structures [2, 3]. The $\mathrm{C6}^{1}$ reservoir in the WY Oilfield is characterized by the 


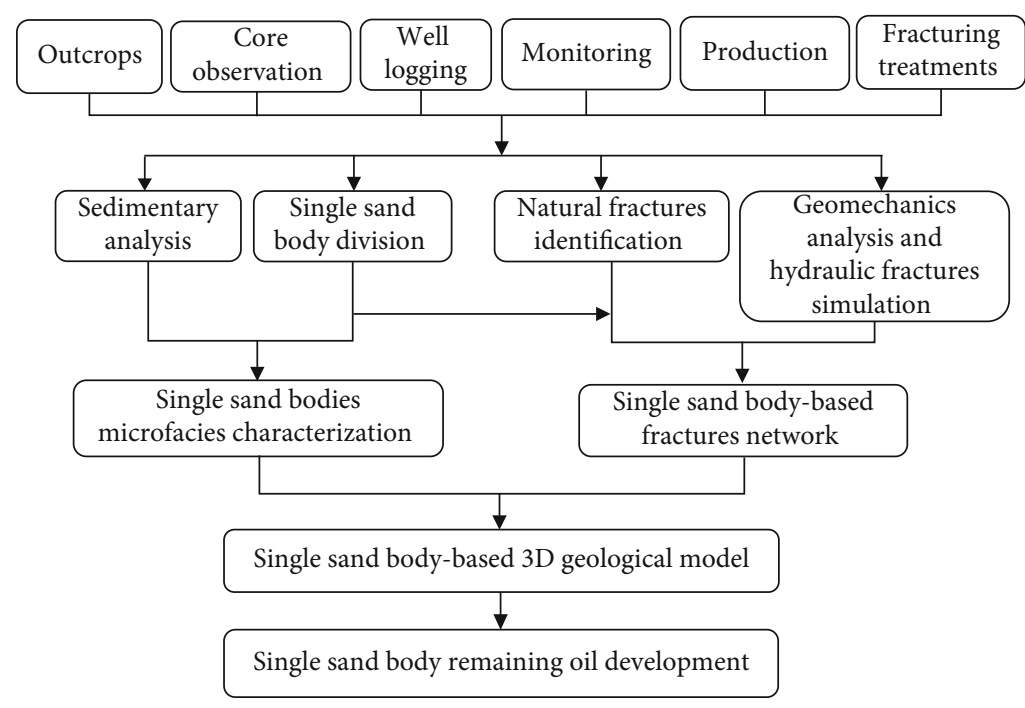

FIGURE 1: The investigation diagram of the integrated approach to tap the remaining oil in the multilayer tight sand reservoirs.

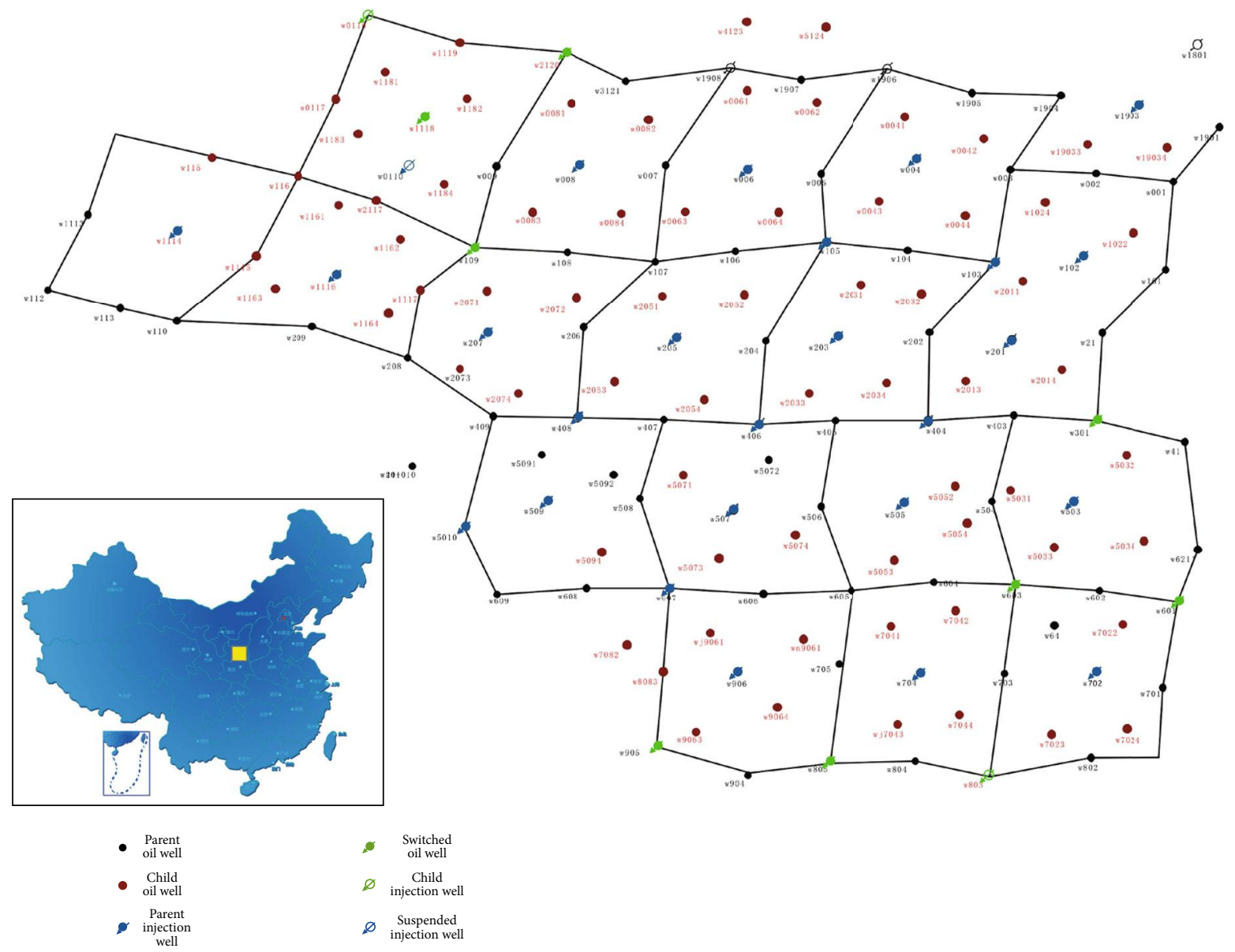

Figure 2: The location and well patterns of the study area. The well type is shown in inset legend.

extra-low permeability, with the average permeability of only approximately $1.2 \mathrm{mD}$ (i.e., $1.2 \times 10^{-3} \mu \mathrm{m}^{2}$ ). Moreover, the average porosity is about $12.4 \%$, while the average original water saturation is appropriately $45 \%$. Thus, this reservoir is a typical low-porosity and low-permeability reservoir, which needs to perform hydraulic fracturing to enhance its oil production.

However, after performing the integrated fracturing on the $\mathrm{C}^{1}{ }^{1}$ reservoir for oil production, many production wells exhibited a high degree of water cut shortly after the 


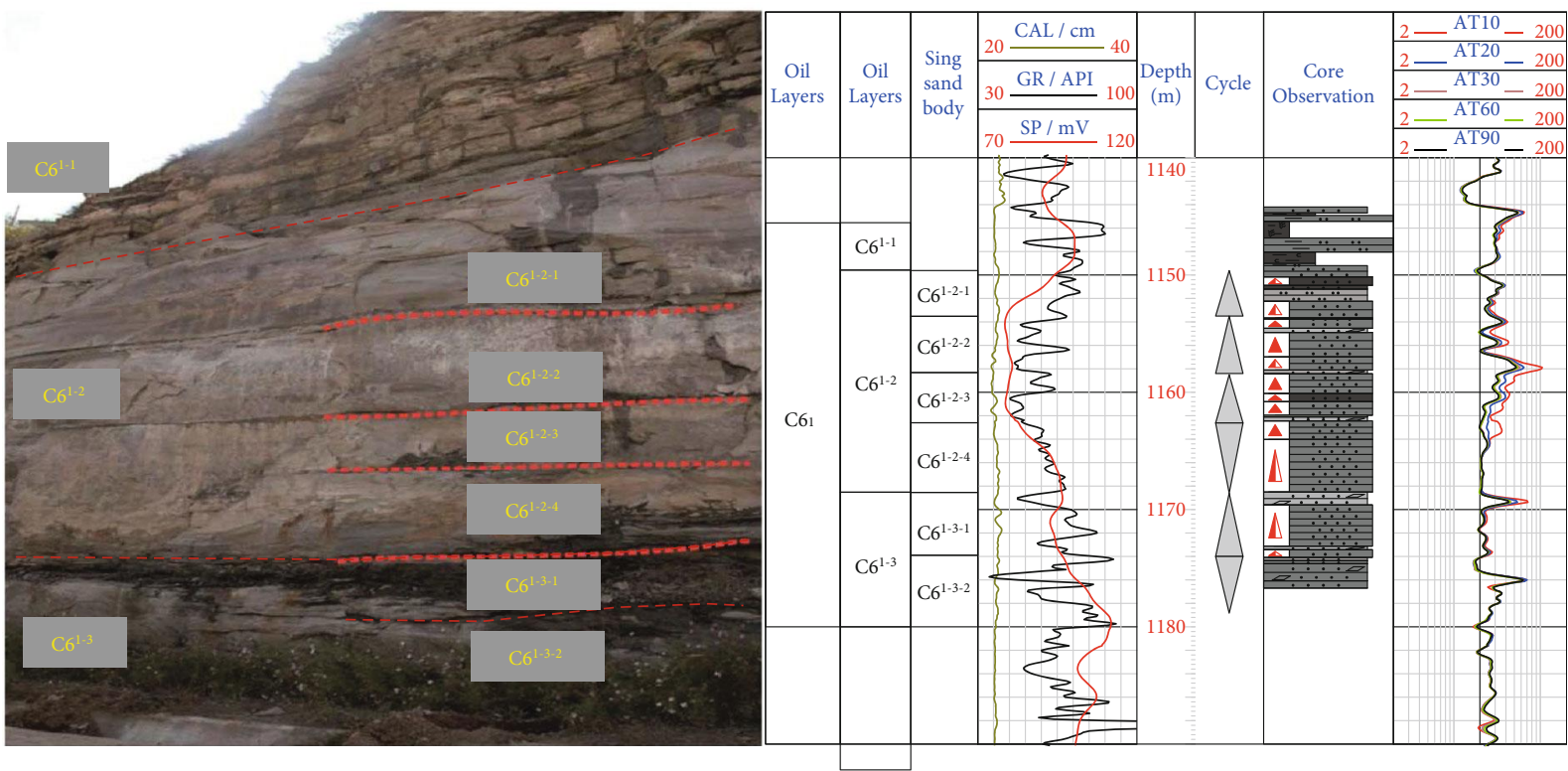

\begin{tabular}{|c|c|c|c|}
\hline & $\begin{array}{c}\text { Calcareous or } \\
\text { muddy interlayer }\end{array}$ & 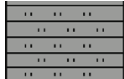 & $\begin{array}{l}\text { Grey } \\
\text { siltstone }\end{array}$ \\
\hline & $\begin{array}{l}\text { Black } \\
\text { mudstone }\end{array}$ & 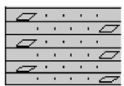 & $\begin{array}{l}\text { Greywhite } \\
\text { calcareous fine sandstone }\end{array}$ \\
\hline & $\begin{array}{c}\text { Grey black } \\
\text { silty mudstone }\end{array}$ & & $\begin{array}{l}\text { Grey black } \\
\text { fine sand }\end{array}$ \\
\hline
\end{tabular}

FIGURE 3: The outcrops, core observation, and well logging features for sand layers. Six sand layers are further divided within $\mathrm{C} 6^{1}$ oil layers. The muddy or calcareous interlayers mark the boundary between two oil layers.

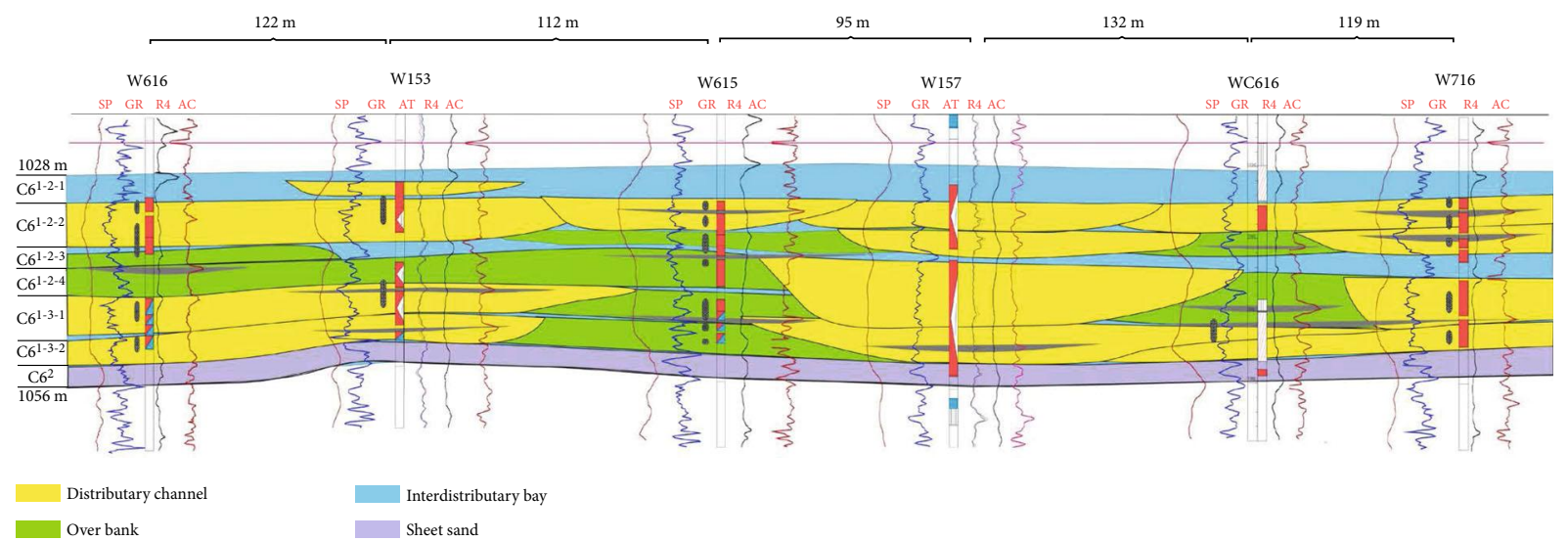

Figure 4: The correlation profile of four sand layers within the $\mathrm{C}^{1}$ oil layers. Four microfacies are identified based on the regional sedimentary setting, core observation, and logging response.

fracturing stimulations. In 2016, 146 fracturing production wells were either shut down or switched to the injection wells due to the high water cut. The water breakthrough was also observed within the $\mathrm{C}^{1}$ oil layers shortly after fracturing operations of particular wells. Its spatial distribution exhibited several lineaments of approximately $\mathrm{NE} 67^{\circ}$ trending $[2,3]$. The reservoir entered a stage of high water cut and low recovery degree as a result of this water breakthrough in many fracturing wells. Previous works have demonstrated that such water breakthrough patterns are linked to the intri- cacy of subsurface fracture networks in heterogeneous multistage sand bodies. Therefore, it is essential to investigate the effect of fracture networks on the waterflooding development and propose the corresponding strategy to tap the remaining oil in the reservoir.

\subsection{Multistage Sand Layer Subdivision and Sedimentary Microfacies Analysis}

3.2.1. Sand Layer Division and Correlation. The $\mathrm{C}^{1}$ oil layer group is divided into the $\mathrm{C}^{1-1}, \mathrm{C}^{1-2}$, and $\mathrm{C}^{1-3}$ oil layer [3, 

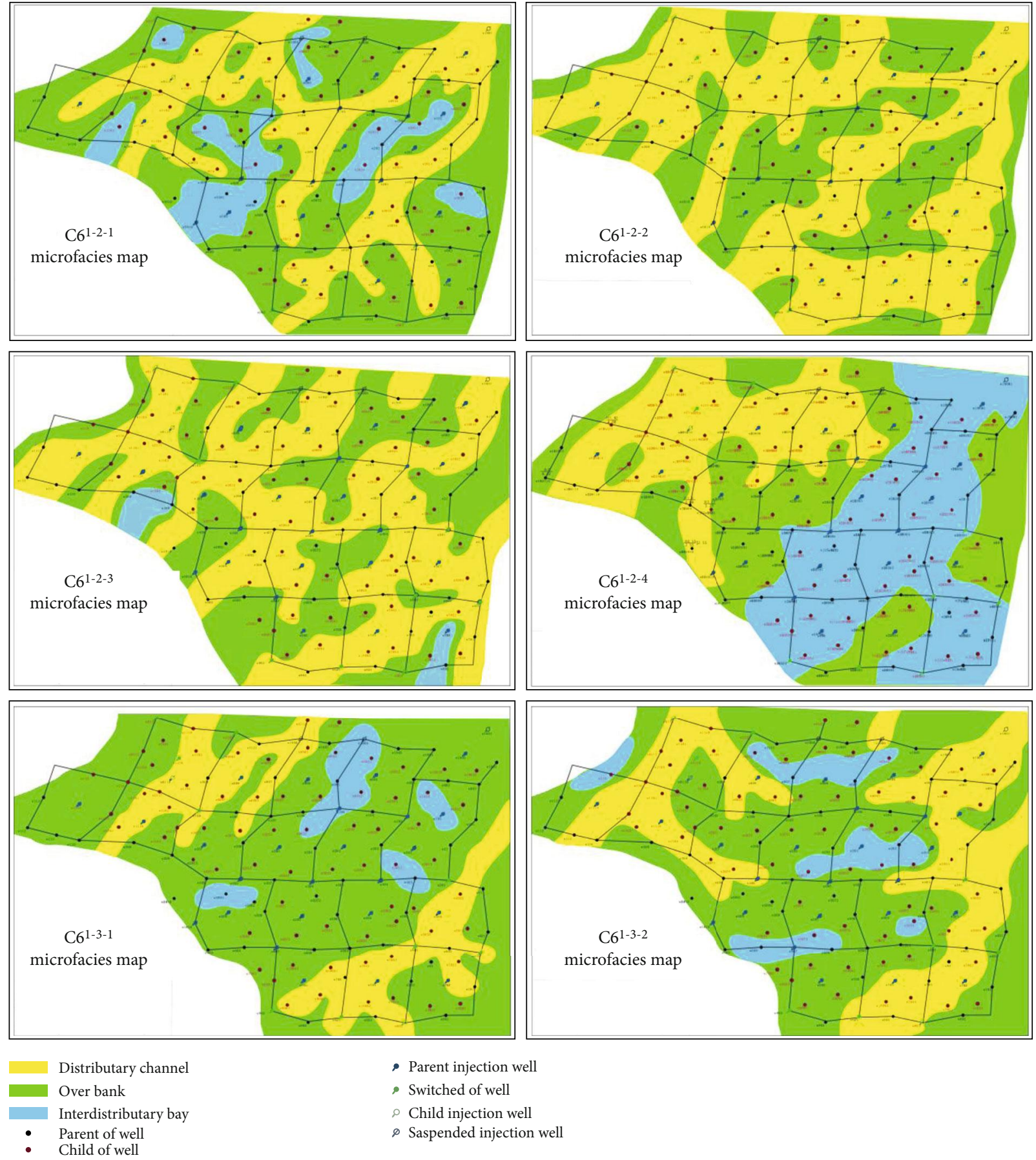

FIGURE 5: The map view of inferred microfacies in the study region. The microfacies maps exhibit the distinctive sedimentary patterns of three major microfacies in six sand layers.

4]. Based on the outcrops and core observation, the $\mathrm{C} 6^{1-1}$ oil layer is primarily composed of siltstone and hence not the pay zone. In contrast, the $\mathrm{C} 6^{1-2}$ and $\mathrm{C} 6^{1-3}$ oil layers consist of oil-saturated fine sandstones and contribute to the majority of oil production. Figure 3 shows the observed outcrops of related sand layers. It is found that the $\mathrm{C}^{1-2}$ and $\mathrm{C}^{1-3}$ oil layers have the features of multistage sand bodies' superposition. Given that the muddy or calcareous interlayers mark the boundary between two adjacent individual sand layers, the $\mathrm{C}^{1-2}$ oil layers could be further subdivided into the $\mathrm{C}^{1-2-1}, \mathrm{C}^{1-2-2}, \mathrm{C}^{1-2-3}$, and $\mathrm{C}^{1-2-4}$ sand layer, whereas the $\mathrm{C} 6^{1-3}$ oil layer into $\mathrm{C} 6^{1-3-1}$ and $\mathrm{C} 6^{1-3-2}$. The thickness of one sand layer is approximately $2 \sim 5 \mathrm{~m}$, consistent with the thickness derived from the logging response.

3.2.2. Microfacies Analysis for Each Sand Layer. The $\mathrm{C}^{1}$ oil layers, as a typical shallow-water platform, were deposited in the sedimentary environment of fan delta front [3]. Based on the classic sedimentary pattern, the microfacies at the well 


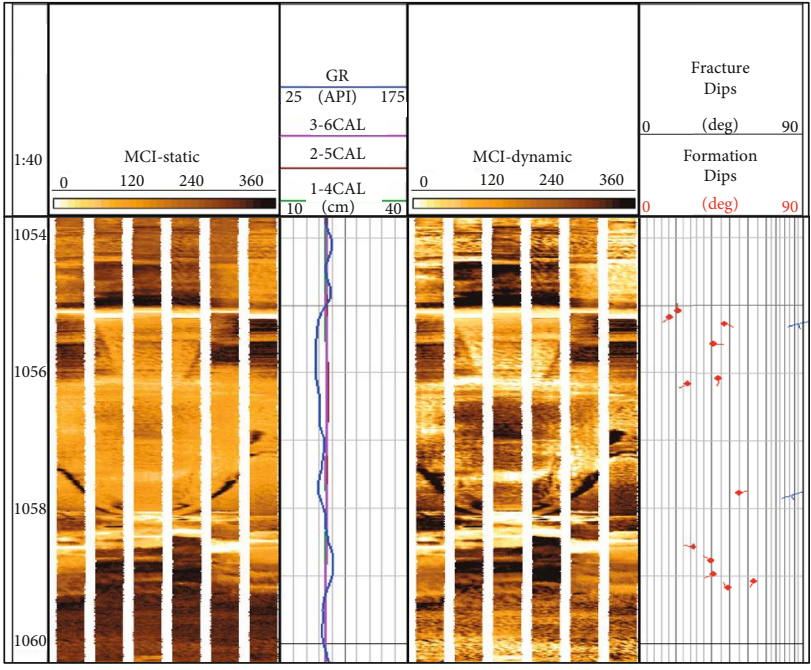

(a)

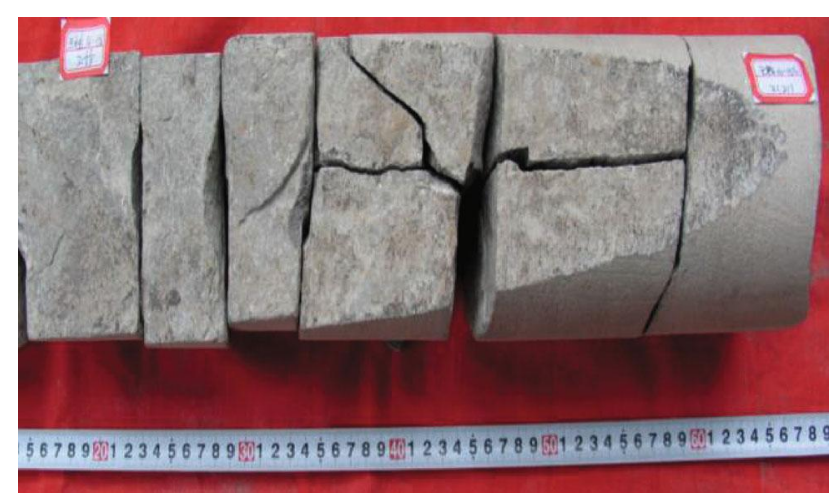

(b)

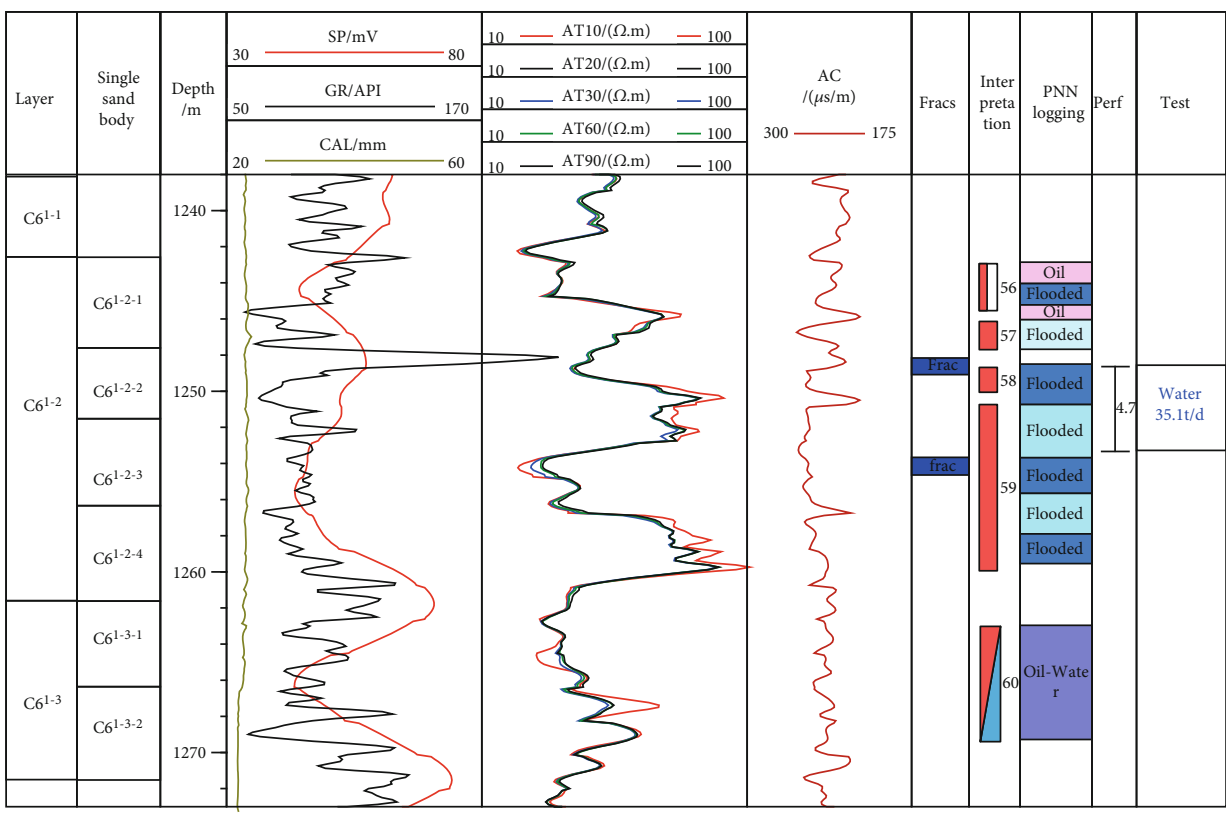

(c)

FIgURE 6: Fracture features of (a) MCI logging, (b) core observation, and (c) conventional well logging in the study area.

TABLE 1: Statistics of natural fracture properties derived from the MCI logging.

\begin{tabular}{|c|c|c|c|c|c|c|c|c|c|}
\hline$\overline{\text { Well }}$ & Depth/m & Lithology & $\operatorname{Dip} /^{\circ}$ & Strike $/^{\circ}$ & Well & Depth/m & Lithology & $\mathrm{Dip} /^{\circ}$ & Strike $^{\circ}$ \\
\hline \multirow{5}{*}{ W15 } & 1033 & Siltstone & 71.4 & 85.3 & \multirow{5}{*}{ W17 } & 1039.9 & Siltstone & 79.4 & 77 \\
\hline & 1038.7 & Fine sandstone & 73.9 & 114.3 & & 1040.6 & Fine sandstone & 81.9 & 39.5 \\
\hline & 1055.3 & Calcareous sandstone & 84.7 & 70.7 & & 1041 & Calcareous sandstone & 82.3 & 46.7 \\
\hline & 1057.8 & Fine sandstone & 77.2 & 68.8 & & 1050.2 & Fine sandstone & 83.3 & 46.9 \\
\hline & 1070.9 & Fine sandstone & 82.4 & 96.2 & & 1064.1 & Muddy siltstone & 87.1 & 20.1 \\
\hline \multirow{2}{*}{ W16 } & \multirow{2}{*}{1118.7} & \multirow{2}{*}{ Siltstone } & \multirow{2}{*}{66.8} & \multirow{2}{*}{72.1} & \multirow{2}{*}{ W18 } & 1018.1 & Siltstone & 79 & 63 \\
\hline & & & & & & 1054.1 & Fine sandstone & 85 & 71 \\
\hline
\end{tabular}

sites are further interpreted from the core observation and logging response. It is shown that the subaqueous distributary channel, interdistributary bay, overbank, and sheet sand developed in the study region in order of decreasing fre- quency (Figure 4). Overall, the sedimentary datum level of the $\mathrm{C}^{1}$ oil layers followed a downward trend, in which the $\mathrm{A} / \mathrm{S}$ value showed a fluctuate decrease. Specifically, in the period of $\mathrm{C}^{2}$, the isolated channel belt generated with a 


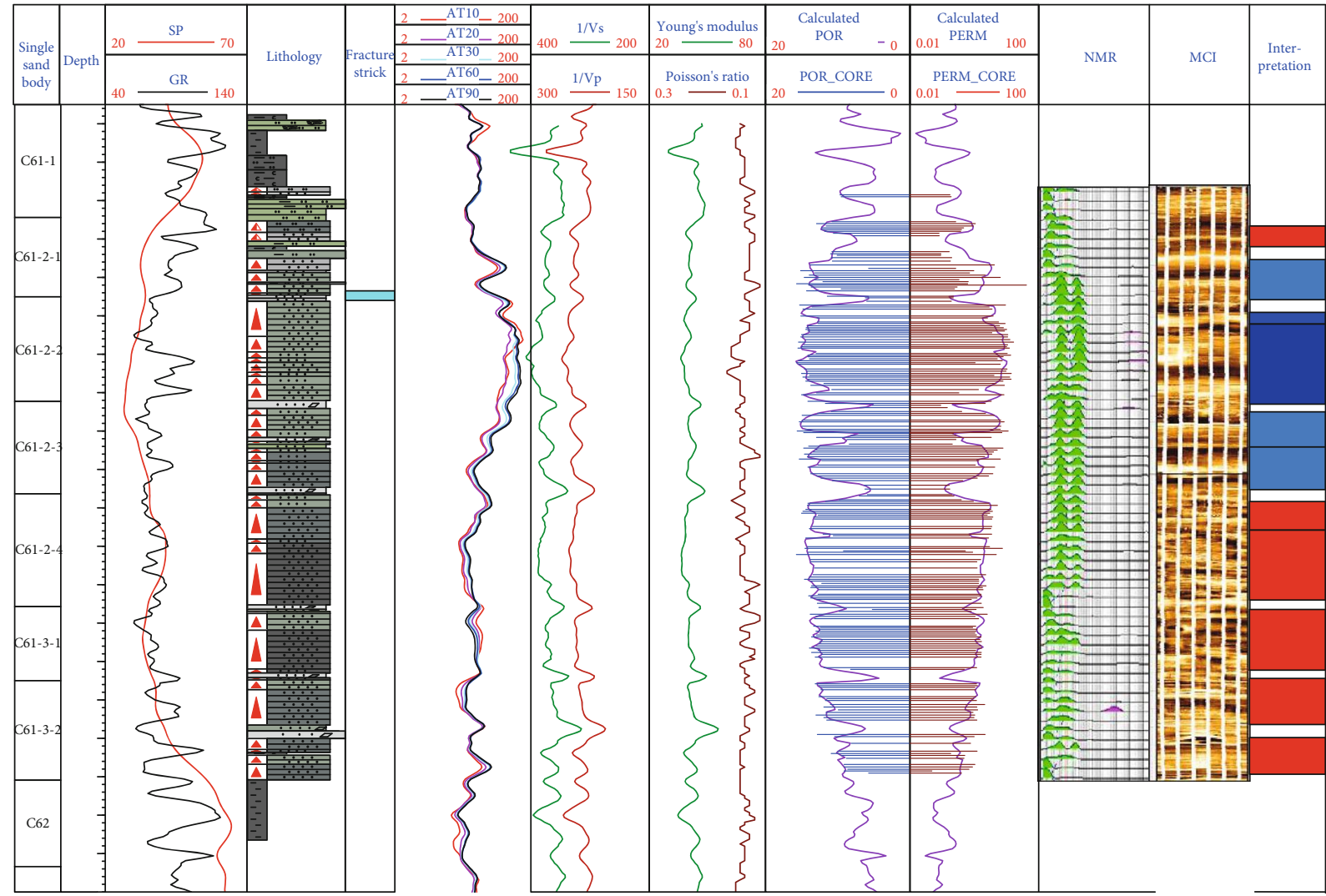

FIGURE 7: The detailed view of logging response and interpretation results of well w155. The lithology profile is derived from the core observation. The fracture strike denotes the interpreted strike of four inferred fractures from the MCI logging. The discrete porosity and permeability data are obtained from the experiment analysis for core samples. The interpretation is based on the comprehensive analysis of flooding tests for core samples. The blue color represents the state of severely waterflooded, whereas the red one denotes the oil layer without waterflooded.

small ratio between the channel and interdistributary bay. In contrast, during the period of $\mathrm{C}^{1-3}$, the distributary channel gradually emerged, and the branch channel began to swing laterally. A notable increase is observed in the deposition scale of the main channel and the branch channel belt. The overbank sediments switched to the silt-fine sandstone from the argillaceous sediments, accompanied by the increasing ratio of the channel to interdistributary bay. The distributary channel continued to grow during the period of $\mathrm{C}^{1-2}$. The ratio of central channel belt to branch channel belt further raised, whereas the interchannel mudstone gradually disappeared. Then, the sand-land ratio reached a local peak value in the $\mathrm{C} 6^{1}$ oil layers.

Figure 5 shows the map view of inferred microfacies in the $\mathrm{C}^{1-2-1}, \mathrm{C}^{1-2-2}, \mathrm{C}^{1-2-3}, \mathrm{C}^{1-2-4}, \mathrm{C}^{1-3-1}$, and $\mathrm{C}^{1-3-2}$ sand layer. It is shown that the distributary channel mainly developed in the $\mathrm{C} 6^{1-2-2}$ and $\mathrm{C} 6^{1-2-3}$ sand layer, in which interdistributary bay microfacies seldom developed. The ratio of sand to formation thickness in these two layers is relatively high in comparison with other sand layers. In the $\mathrm{C} 6^{1-2-1}$ sand layer, two central distributary channels and several branch channels are developed in the study area. The overbank sand deposits on both sides of the channel. In the C6 ${ }^{1-2-2}$ sand layer, the distributary channel microfacies concentrate in the west area while the overbank mainly develops in the east region. The distribution of microfacies in the $\mathrm{C}^{1-}$ ${ }^{3-1}$ sand layer displayed nearly the same pattern as that of the $\mathrm{C}^{1-3-2}$ sand layer. Two branches of distributary channel generate in the west and east area in these two sand bodies, while the over banks scattered distribute in the corresponding sand layer. The interlayer usually formulates between the main channel and the overbank microfacies, which would function as a barrier to restrain the spatial propagation of hydraulic fractures during fracturing operations.

\subsection{Determination of Hydraulic-Natural Fracture Networks}

3.3.1. Preexisting Natural Fracture Identification. The natural fractures in the $\mathrm{C}^{1}{ }^{1}$ reservoir have been ascribed to the tectonic movement in the Yanshan and Xishan period of Mesozoic $[17,18]$. Based on the previous studies on the associated outcrops, natural fractures generated with an orientation range of NE $66^{\circ} \sim 85^{\circ}$. This range of orientation agrees with that of the maximum principal stress $\left(S_{\mathrm{H} \max }\right)$ in the WY Oilfield, which is $\mathrm{NE} 67^{\circ}$ according to the comprehensive analysis of the multiscale database [2].

The natural fractures could be recognized from the Micro-Conductivity Imager (MCI) logging, core observation, production-injection response, and field test. Specifically, the natural fractures were characterized by the open-bowl-like 
TABle 2: Parameter statistics of hydraulic and mechanical parameters for each sand bodies.

\begin{tabular}{|c|c|c|c|c|c|c|c|}
\hline Sand layer & & $\mathrm{C}_{2-1}^{1-}$ & $\mathrm{C}_{2-2}^{1-}$ & $\mathrm{C}_{2-3}^{1-}$ & $\mathrm{C}_{2-4}^{1-}$ & $\begin{array}{c}\mathrm{C}^{1-} \\
3-1\end{array}$ & $\mathrm{C}_{3-2}^{1-}$ \\
\hline \multirow{3}{*}{ Por } & Min & 0.01 & 0.02 & 0.01 & 0.01 & 0.01 & 0.01 \\
\hline & Avg & 0.128 & 0.139 & 0.146 & 0.139 & 0.131 & 0.124 \\
\hline & Max & 0.22 & 0.206 & 0.222 & 0.21 & 0.218 & 0.188 \\
\hline \multirow{3}{*}{$\begin{array}{l}\text { Perm/ } / \times 10^{-} \\
{ }^{3} \mu \mathrm{m}^{2}\end{array}$} & Min & 0.1 & 0.09 & 0.1 & 0.1 & 0.1 & 0.09 \\
\hline & Avg & 0.72 & 2.78 & 3.16 & 2.67 & 2.49 & 1.31 \\
\hline & Max & 6.52 & 17.92 & 111.6 & 49.73 & 83.3 & 14 \\
\hline \multirow{3}{*}{$E / G P a$} & Min & 33.8 & 32.95 & 30.4 & 35.2 & 33.4 & 34.9 \\
\hline & Avg & 43.2 & 43.5 & 44.1 & 42.2 & 43.2 & 44.3 \\
\hline & Max & 57.8 & 58.7 & 55.4 & 56.7 & 54.8 & 58.6 \\
\hline \multirow{3}{*}{$v$} & Min & 0.18 & 0.19 & 0.19 & 0.2 & 0.18 & 0.19 \\
\hline & Avg & 0.208 & 0.212 & 0.235 & 0.232 & 0.208 & 0.211 \\
\hline & $\operatorname{Max}$ & 0.32 & 0.30 & 0.38 & 0.36 & 0.39 & 0.38 \\
\hline
\end{tabular}

pattern in the MCI logging, shown in Figure 6(a). The dip angle of this fracture is interpreted to be $75^{\circ}$. Table 1 shows the statistics of natural fractures properties (i.e., strike and dip) detected from the MCI logging data of four wells. It is shown that natural fractures in this region are mainly NEtrending high-angle fractures, with a dip range of $66.8^{\circ}$ to $87.1^{\circ}$ and strike range NE $20.1^{\circ}$ to NE $114.3^{\circ}$. Moreover, some core samples also exhibit a similar fracture pattern. Figure 6(b) depicts a natural fracture with a height larger than $0.7 \mathrm{~m}$ and a dip angle of approximately $80^{\circ}$.

Additionally, the existence of natural fractures is also characterized by the abnormality in the conventional well logging. As shown in Figure 6(c), the magnitude of the gammaray $\log (\mathrm{GR})$ is abnormally high at a depth of $1248.9 \mathrm{~m}$ in this well. This abnormality is possibly ascribed to the existence of natural fractures because the radioactive uranium in the reservoir could be precipitated inside the fractures, leading to an unusually high magnitude of gamma-ray response. Similarly, given that the drilling fluids flowed into the fractures and reduced the measured formation resistivity, the deep resistivity (AT90) at the same depth is relatively low in comparison with other layers. Moreover, the interpretation of Pulsed NeutronNeutron (PNN) logging further verifies the existence of natural fracture developed, which is interpreted as the waterflooded state at this depth. The production test for this layer shows the pure water production of $35.1 \mathrm{t}$ per day. These various features indicate the existence of natural fractures at the specific depth of this well (Figure 6(c)).

In addition, the natural fractures are mainly in an unfilled state based on the core observation and MCI logging [17]. Under the high in situ formation pressure $(11.2 \mathrm{MPa}$ in $1040 \mathrm{~m}$ ), the unfilled fractures temporarily closed. However, as the long-term water flooding continued, the formation pressure increases correspondingly, and these fractures would be stimulated and reopened as a high permeable zone [2]. In this scenario, the hydraulic fractures propagate and connect with aforementioned reopened natural fractures, which might account for the water breakthrough phenomenon is frequently observed shortly after the fracturing operations in this area.
3.3.2. Geomechanical Analysis and Hydraulic Fracture Propagation. The propagation of hydraulic fractures is simulated based on the geomechanical properties and real-time treatment data. Specifically, geomechanical properties (i.e., Poisson's ratio and Young's modulus) are derived from the data of velocity and density logging, using the following expressions [19]:

$$
\begin{gathered}
v=\frac{0.5 *\left(V_{p} / V_{s}\right)^{2}-1}{\left(V_{p} / V_{s}\right)^{2}-1}, \\
E=\frac{\rho V_{s}\left(3 V_{p}^{2}-4 V_{s}^{2}\right)}{V_{p}^{2}-V_{s}^{2}},
\end{gathered}
$$

where $V_{s}$ is the S-wave velocity, $\mathrm{m} / \mathrm{s} ; V_{p}$ is the $\mathrm{P}$-wave velocity, $\mathrm{m} / \mathrm{s} ; v$ is the Poisson's ratio; $E$ is the Young's modulus, $\mathrm{GPa}$; and $\rho$ is the density, $\mathrm{kg} / \mathrm{m}$. Well w155 is logged to the target zone and measured the $\mathrm{P}$-wave $\left(V_{p}\right)$ and $\mathrm{S}$-wave velocities $\left(V_{s}\right)$. The regression expression is derived from the relationship between the velocity logging and other conventional logging for this well. Next, the calculation of geomechanical parameters is then extended to other wells, using the following regression expression:

$$
\frac{1}{V_{s}}=2.2552+1.5121 * \frac{1}{V_{p}}+0.056 * \mathrm{GR}-0.00484 * \mathrm{RT},
$$

where GR is the gamma-ray, API, and RT is the deep formation resistivity, $\Omega \cdot \mathrm{m}$.

The changes of in situ stress fields in response to hydraulic fracturing are considered in this work. The induced stress tensors for the random spatial point in proximity to hydraulic fractures are calculated by the following expressions [20]:

$$
\begin{aligned}
& \sigma_{x}{ }^{\prime}= P \frac{r}{a}\left(\frac{a^{2}}{r_{1} r_{2}}\right)^{3 / 2} \sin \theta \sin \frac{3}{2}\left(\theta_{1}+\theta_{2}\right)+P \\
& \cdot\left[\frac{r}{\left(r_{1} r_{2}\right)^{1 / 2}} \cos \left(\theta-\frac{1}{2} \theta_{1}-\frac{1}{2} \theta_{2}\right)-1\right], \\
& \sigma_{z}{ }^{\prime}=-P \frac{r}{a}\left(\frac{a^{2}}{r_{1} r_{2}}\right)^{3 / 2} \sin \theta \sin \frac{3}{2}\left(\theta_{1}+\theta_{2}\right)+P \\
& \cdot {\left[\frac{r}{\left(r_{1} r_{2}\right)^{1 / 2}} \cos \left(\theta-\frac{1}{2} \theta_{1}-\frac{1}{2} \theta_{2}\right)-1\right], } \\
& \sigma_{y}{ }^{\prime}=\mu\left(\sigma_{x}{ }^{\prime}+\sigma_{z}{ }^{\prime}\right),
\end{aligned}
$$

where $\sigma_{x}{ }^{\prime}, \sigma_{y}{ }^{\prime}$, and $\sigma_{z}{ }^{\prime}$ are the induced stress tensors in $x, y$, and $z$ axle; $P$ is the pore pressure within the hydraulic fracture; $r, r_{1}$, and $r_{2}$ are the distance between the spatial point to the centre, top, and bottom of the hydraulic fracture; and $\theta, \theta_{1}$, and $\theta_{2}$ are the angle between the spatial point to the centre, top, and bottom of the hydraulic fracture with respect 


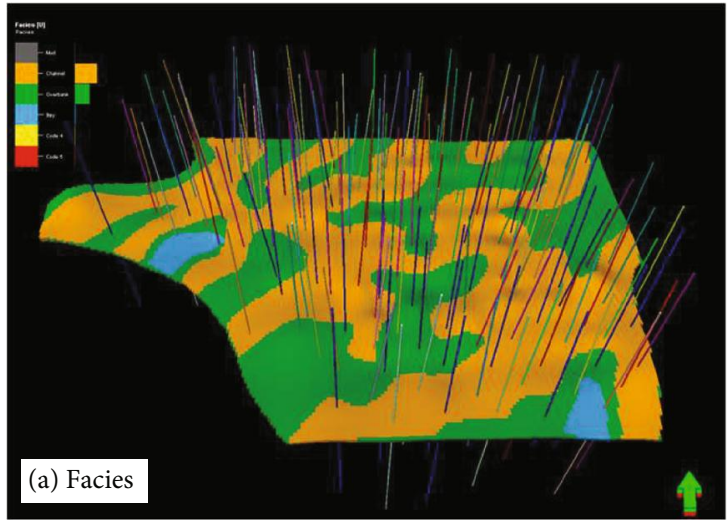

(a)

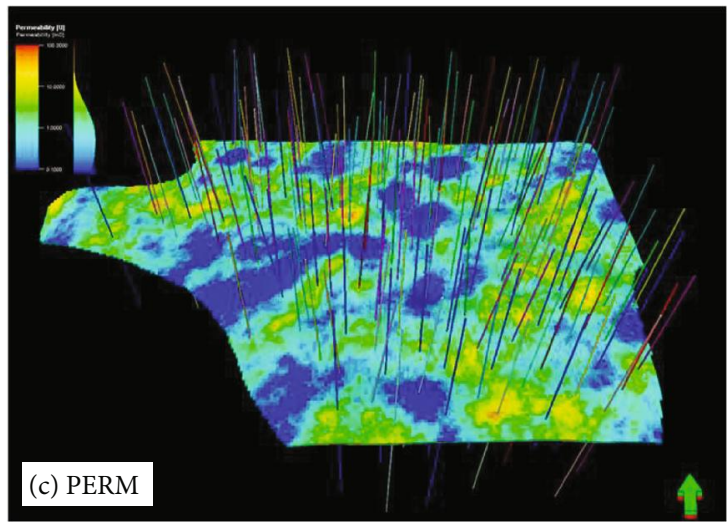

(c)

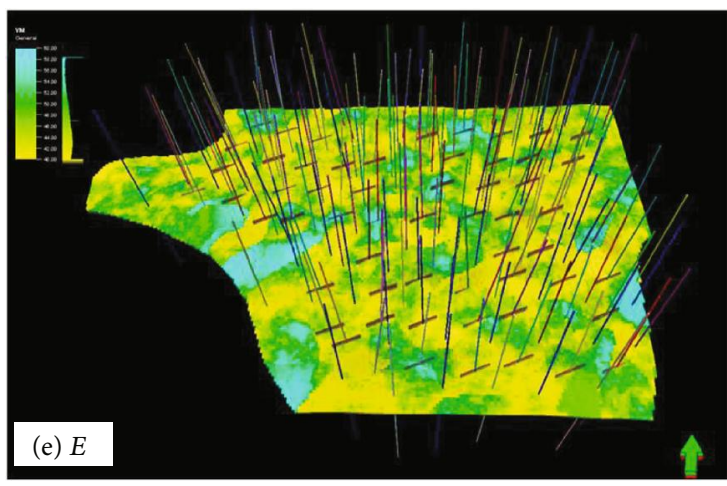

(e)

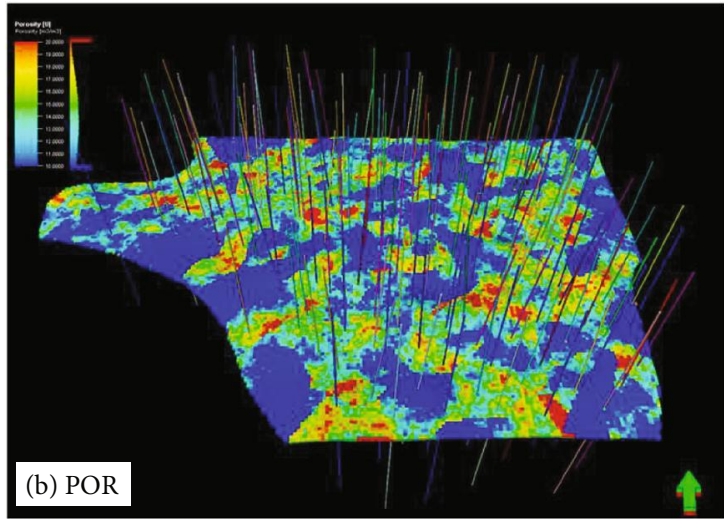

(b)

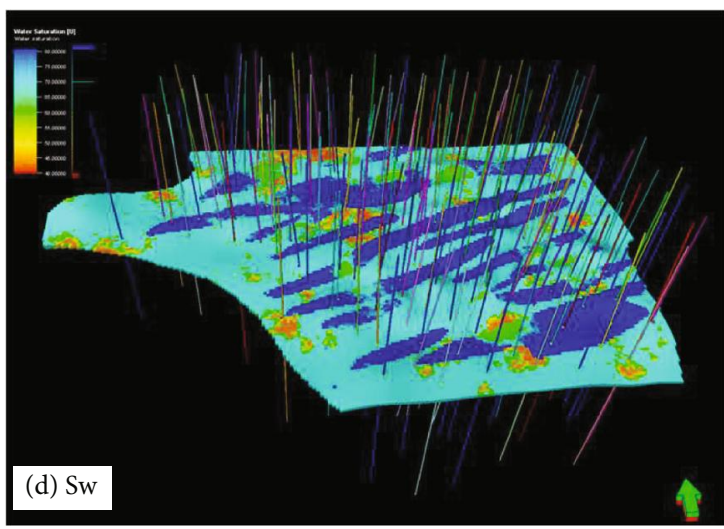

(d)

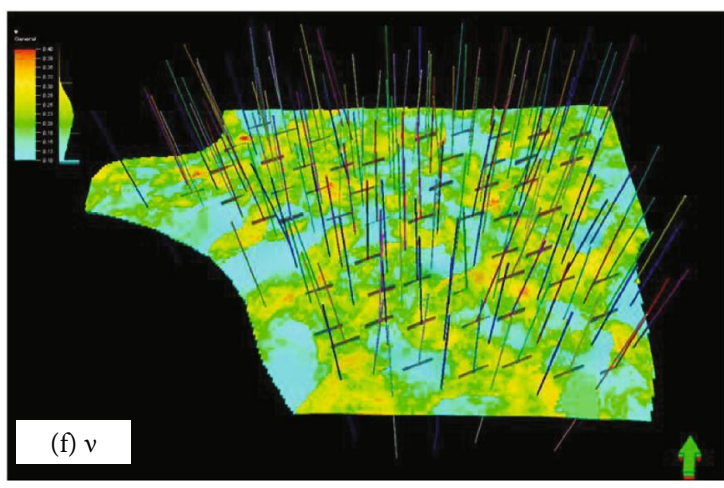

(f)

FIGURE 8: The 3D geological model restrained by the microfacies and combined fractures in the $\mathrm{C}^{1-2-3}$ sand layer. (a) The microfacies model. (b) The porosity model. (c) The permeability model. (d) The water saturation model. It follows the water breakthrough pattern shown in Figure 11. (e) The Young's modulus model. (f) The Poisson's ratio model.

to $z$-axis. These equations are used to determine the new ambient stress before the refracturing operations.

Similarly, the hydraulic properties (i.e., porosity and permeability) are derived from the regression equations based on the logging data, which is given by:

$$
\begin{gathered}
\mathrm{POR}=2.7654 * e^{0.1194 * X}, \\
X=-11.5706+0.0999 * \mathrm{AC}-0.03571 * \mathrm{GR}^{\prime}, \\
\mathrm{PERM}=e^{-5.2537-0.02335 * \mathrm{GR}^{\prime}+0.40555 * \mathrm{POR}+0.01247 * \mathrm{RT}^{\prime},}
\end{gathered}
$$

where POR is the porosity; PERM is the permeability, $\mu \mathrm{m}^{2}$; $\mathrm{GR}^{\prime}$ is the normalized gamma-ray, which is calculated by ( $\left.\mathrm{GR}-\mathrm{GR}_{\min }\right) /\left(\mathrm{GR}_{\max }-\mathrm{GR}_{\min }\right)$; and $\mathrm{RT}^{\prime}$ follows the same calculation. Figure 7 shows the detailed view of logging response and interpretation results of well w155. It is shown that the calculated porosity and permeability match well with the physical properties of core samples. The Magnetic Resonance Imaging (NMI) logging displays a feature of the bimodal-pattern, indicating that the pore structures contain both the macropore and micropore structure within the reservoir. Normally, the movable oil is filled in the macropore 


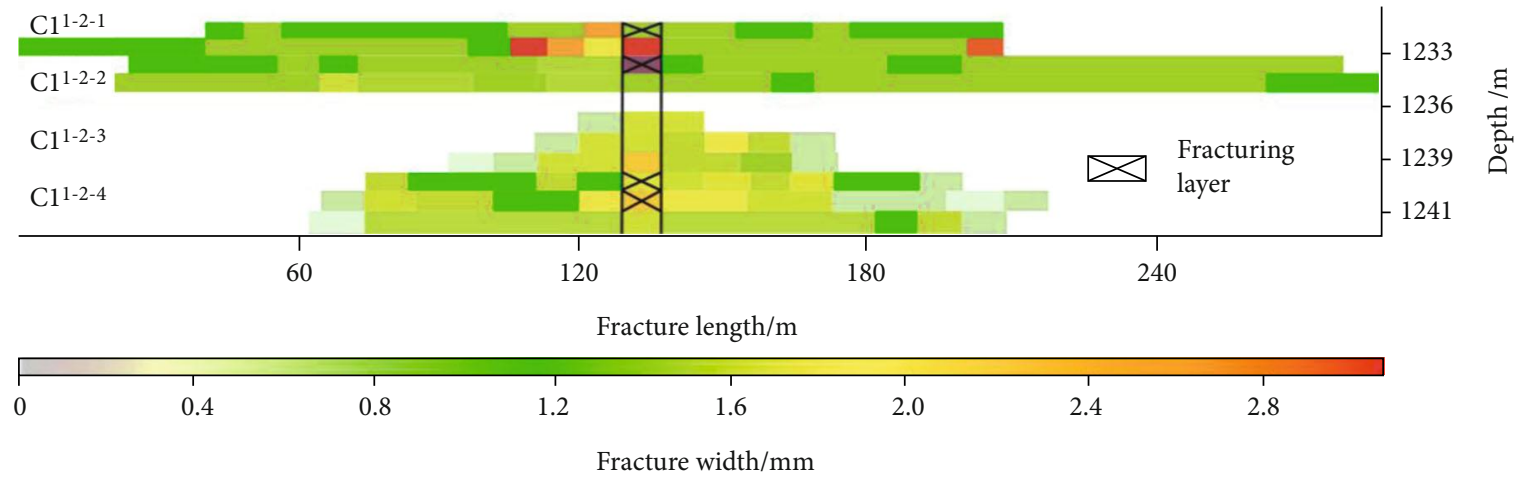

Figure 9: The simulated hydraulic fractures of each sand layer in well wj9061. The asymmetrical hydraulic fractures are observed in these sand layers.

TABLE 3: Statistics of fracture properties interpreted from the microseismicity monitoring.

\begin{tabular}{|c|c|c|c|c|c|}
\hline Well & Strike/ ${ }^{\circ}$ & $\begin{array}{l}\text { Fracture full } \\
\text { length/m }\end{array}$ & $\begin{array}{c}\text { East } \\
\text { length/m }\end{array}$ & $\begin{array}{c}\text { West } \\
\text { length/m }\end{array}$ & $\begin{array}{l}\text { Fracture } \\
\text { height } / \mathrm{m}\end{array}$ \\
\hline W0063 & $\begin{array}{l}\mathrm{NE} \\
50.1\end{array}$ & 102.2 & 46.7 & 55.6 & 11.3 \\
\hline W2052 & $\begin{array}{l}\text { NW } \\
61.2\end{array}$ & 200.0 & 121.3 & 78.7 & 16.0 \\
\hline W0211 & $\begin{array}{c}\mathrm{NE} \\
54.0\end{array}$ & 165.3 & 98.7 & 66.6 & 13.3 \\
\hline XW21 & $\begin{array}{l}\mathrm{NE} \\
60.4\end{array}$ & 205.3 & 69.4 & 135.9 & 14.7 \\
\hline W5053 & $\begin{array}{c}\mathrm{NE} \\
46.4\end{array}$ & 160.71 & 91.9 & 68.8 & 4.2 \\
\hline W5034 & $\begin{array}{l}\mathrm{NE} \\
63.2\end{array}$ & 167.45 & 92.63 & 74.82 & 5.8 \\
\hline W5032 & $\begin{array}{l}\text { NW } \\
75.0\end{array}$ & 170.4 & 72.17 & 98.27 & 7.0 \\
\hline W5054 & $\begin{array}{l}\mathrm{NE} \\
65.0\end{array}$ & 217.2 & 145.0 & 72.2 & 55.0 \\
\hline
\end{tabular}

while the irreducible water is filled in the micropore. Moreover, the interpretation is based on the comprehensive analysis of flooding tests for core samples. The blue color represents the state of severely waterflooded, whereas the red one denotes the oil layer without waterflooded. Thus, the severely waterflooding layer usually has a relatively high porosity and permeability (Figure 7).

Table 2 shows the statistics of hydraulic and mechanical parameters for each sand bodies. It is shown that the Poisson's ratio, Young's modulus, porosity, and permeability in six sand layers range from $0.18 \sim 0.39,30.4 \sim 58.7 \mathrm{GPa}$, $0.01 \sim 0.222$, and $0.09 \sim 111.6 \times 10^{-3} \mu \mathrm{m}^{2}$, respectively. The $3 \mathrm{D}$ view for these parameters is shown in Figure 8. This heterogeneity of hydraulic and mechanical properties in six sand layers further verifies the superposition pattern of multistage channels, indicating the possible asymmetric propagation of hydraulic fractures after performing fracturing operations.

The real-time treatment data are utilized to determine the fracture half-length by history-matching the net operational pressure during the fracturing stimulation. First, the treat- ment datasets are established, including the treatment pressure, slurry rate, and proppant concentration. Next, the heat conduction, formation parameters, and wellbore structure are introduced to simulate the stimulation process under subsurface conditions. The fracturing fluid and proppant types are then determined to calculate the closure pressure and net operational pressure. Finally, the history matching of net operational pressure is conducted to determine the propagation of hydraulic fractures in terms of fracture halflength.

Figure 9 shows the simulated results of hydraulic fractures for well wj9061 after performing integrated fracturing for the whole $\mathrm{C}^{1}$ oil layers. It is worth noting that the hydraulic fractures fail to connect the $\mathrm{C}^{1-2-2}$ with $\mathrm{C} 6^{1-2-3}$ sand layers vertically, which is ascribed to the existence of the muddy interlayer between two layers. Moreover, the fractures propagated laterally with an asymmetrical pattern in each sand layer ([4]). It is also shown that hydraulic fractures in the $\mathrm{C}^{1-2-2}$ and $\mathrm{C}^{1-2-3}$ sand layer extended further than that of $C 6^{1-2-3}$ and $C 6^{1-2-4}$ layer. This difference is attributed to the geomechanics variety for different sand layers (Table 2).

The simulated hydraulic fractures can be further calibrated by the analysis of microseismic monitoring datasets. Table 3 shows the statistics of inferred hydraulic fractures, which are interpreted from the microseismic monitoring. It is found that the full length of hydraulic fractures ranges from $102 \mathrm{~m}$ to $217 \mathrm{~m}$, with an average value of $178 \mathrm{~m}$. The variety of east and west wing of hydraulic fractures further corroborates the asymmetric pattern. The height of hydraulic fractures has a variety of $4.2 \mathrm{~m} \sim 16.0 \mathrm{~m}$, indicating the possible irregular distribution of muddy or calcareous interlayers between different sand layers. The spatial propagation of hydraulic fractures is then determined from the comprehensive analysis.

3.3.3. Hydraulic-Natural Fracture Networks and Water Breakthrough. The fracture networks are first determined by analysing the waterflooded state of coring wells. Figure 7 shows the distinctive waterflooded state in different sand layers of well W155. It is found that the severely waterflooded thin layer $(1040.4 \sim 1044.6 \mathrm{~m})$ is spatially adjacent to the inferred fractures $(1038.7-1039.2 \mathrm{~m})$ in the $\mathrm{C}^{1-2-3}$ layer. 

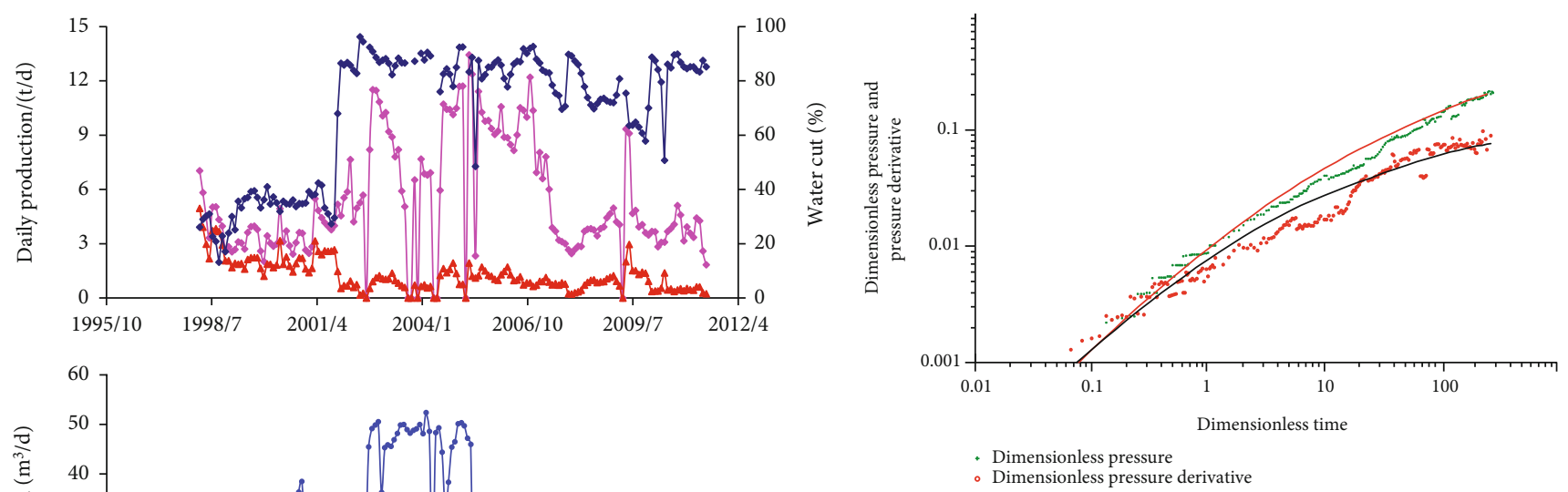

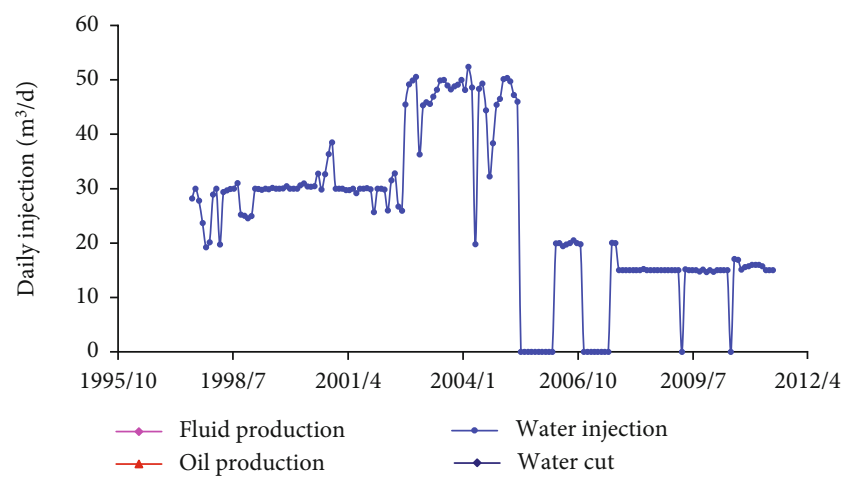

(a)

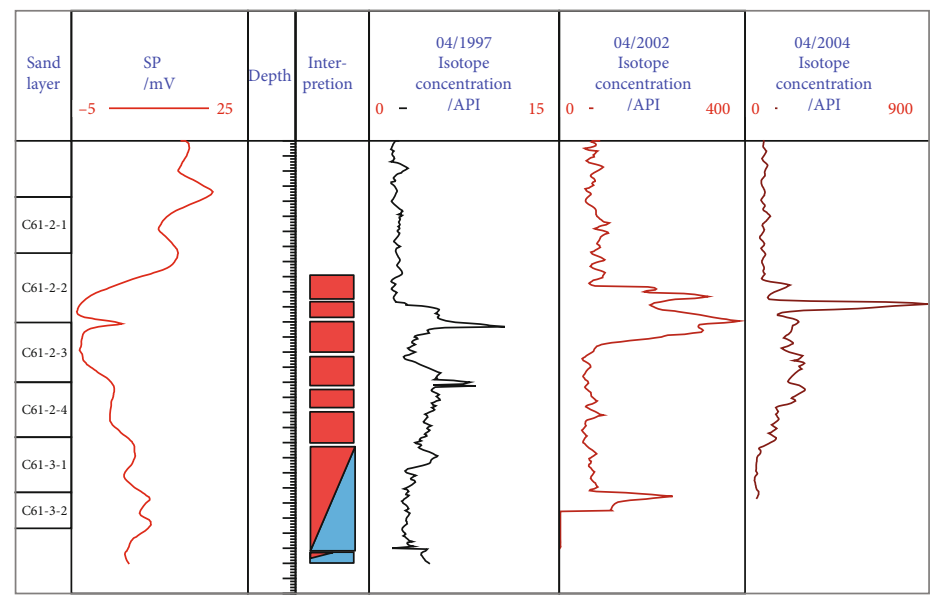

(c)

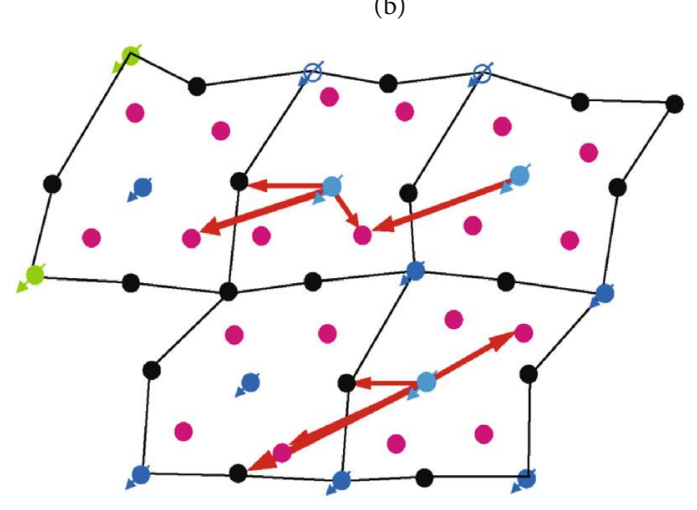

(d)

FIGURE 10: (a) The injection-production response shows the possible existence of fractures. A sharp increase in the water cut of production wells was accompanied by the corresponding increase in the injection amount of injection wells. (b) Well test analysis for an injection well. The effective formation permeability and full fracture length are interpreted to be $21.1 \times 10^{-3} \mu \mathrm{m}^{2}$ and $442 \mathrm{~m}$, respectively. (c) The evolution of the water absorption profile. The thickness of water absorption exhibits a decreasing trend with time, indicating the growing up of fracture networks. (d) Tracer monitoring for three injection wells. The tracer flow exhibits a dominant orientation of NE $67^{\circ}$.

Given that the vertical permeable features of each sand layer, this severely waterflooded state is ascribed to the vertical connection of fractures within the sand layers. Moreover, some features of injection-production responses also indicate the growing up of the fracture networks [21, 22]. Figure 10(a) shows the water injection and production data of wells W6 and W7, respectively. After 45 months of production, the water cut of well W7 rose rapidly from $35 \%$ up to $90 \%$, leading to the shut-in of production operations on 10 January 2012. Simultaneously, the water injection volume of the well W6 showed a sudden increase from $30 \mathrm{~m}^{3} / \mathrm{d}$ to $50 \mathrm{~m}^{3} / \mathrm{d}$. The sharp increases in the water cut of production wells and injection volume of injection wells are possibly attributed to the fracture network that connect both wells. Specifically, the long-term water injection activates the potential fracture networks, leading to a rapid rise of water cut and a sharp decrease in oil production.

Furthermore, the effective reservoir permeability reaches up to $21.1 \times 10^{-3} \mu \mathrm{m}^{2}$, based on the interpretation of well test for an injection well (Figure 10(b)). This high permeability, in comparison with the average matrix permeability $\left(1.2 \times 10^{-3} \mu \mathrm{m}^{2}\right)$, indicates the potential existence of fractures developed in this well. The full length of inferred fractures is interpreted to be approximately $442 \mathrm{~m}$, exceeding 


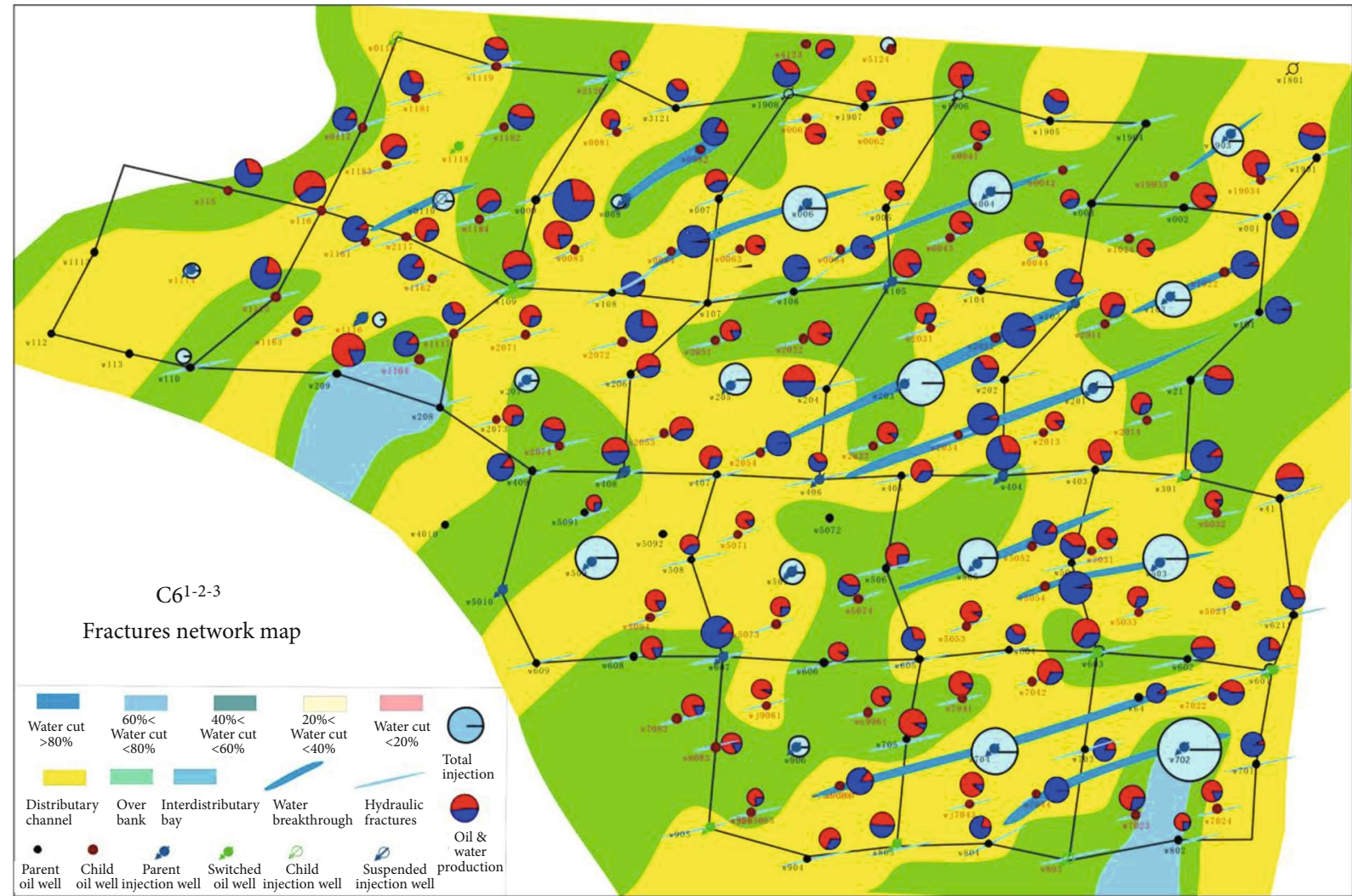

FIGURE 11: The water breakthrough controlled by the fracture networks in the $\mathrm{C}^{1-2-3}$ sand layer. The light blue circle denotes the cumulative injection volume of injection wells. The short line overlapped the production wells show the hydraulic fractures. The long blue belt illustrates the combined hydraulic-natural fracture. The base map was the microfacies in the $\mathrm{C}^{1-2-3}$ sand layer.

the potential extent of hydraulic fractures propagation and verifying the involvement of natural fractures. Moreover, the evolution features of the water absorption profile for injection wells illustrate the dynamic behavior of hydraulicnatural fractures. Figure 10(c) shows that the water absorption concentrated at a thin layer of $\mathrm{C}^{1-2-2}$ from the onset of water injection. The thickness of water absorption exhibited a decreasing trend along with the long-term water injection. This evolution pattern indicates that hydraulic fractures continued propagating within the sandstone layer until connect with the preexisting natural fractures, forming the hydraulic-natural fracture networks, which further affect the water breakthrough in each sand layer.

Besides the network identification for single wells, some field tests could also provide insights into spatial distribution for the hydraulic-natural fracture networks. The tracer monitoring demonstrates the spatial distribution of potential combined fractures based on the concentration and flow velocity of the monitored tracer. Figure 10(d) shows the tracer monitoring results for three injection wells. It is found that the fluid from the injection wells could diffuse over thousands of meters to waterflood the production wells, with a dominant orientation of approximately NE $70^{\circ}$. Overall, the comprehensive analysis is conducted to integrate the results of injection-production response, well test analysis, absorption profile evolution, and tracer tests.

Figure 11 illustrates the water breakthrough restrained by the hydraulic-natural fracture networks in the $\mathrm{C}^{1-2-3}$ layer.
It is shown that the water breakthrough lineaments follow the orientation of approximately NE $67^{\circ}$ with the full length of combined fractures ranging from $292 \mathrm{~m}$ to $2,101 \mathrm{~m}$. The water breakthrough originates from the injection wells with a high amount of injection volume. This large injection provides the driving force for the growing up of the combined fractures. Moreover, the water breakthrough usually occurs within the microfacies of distributary channels, probably owing to the relatively high permeability in this kind of microfacies. Overall, the water breakthrough pattern is primarily ascribed to the spatial distribution of the hydraulicnatural fracture networks and sedimentary microfacies in each sand layer.

\subsection{Remaining Oil Tapping Based on 3D Fine Geological Model}

3.4.1. 3D Integrated Geological Modeling. The 3D geological model is finally established by integrating previous results of single sand layer subdivision, microfacies analysis, and fracture network characterization. Specifically, the results of the sand layer subdivision are first utilized to build the structural model for each sand layer. The physical properties (i.e., porosity, permeability, and water saturation) at the well sites are then incorporated into the structural model. Next, the distribution of microfacies and combined fracture networks in each sand layers are introduced into the model. The matrix and fracture properties are finally simulated, which are 


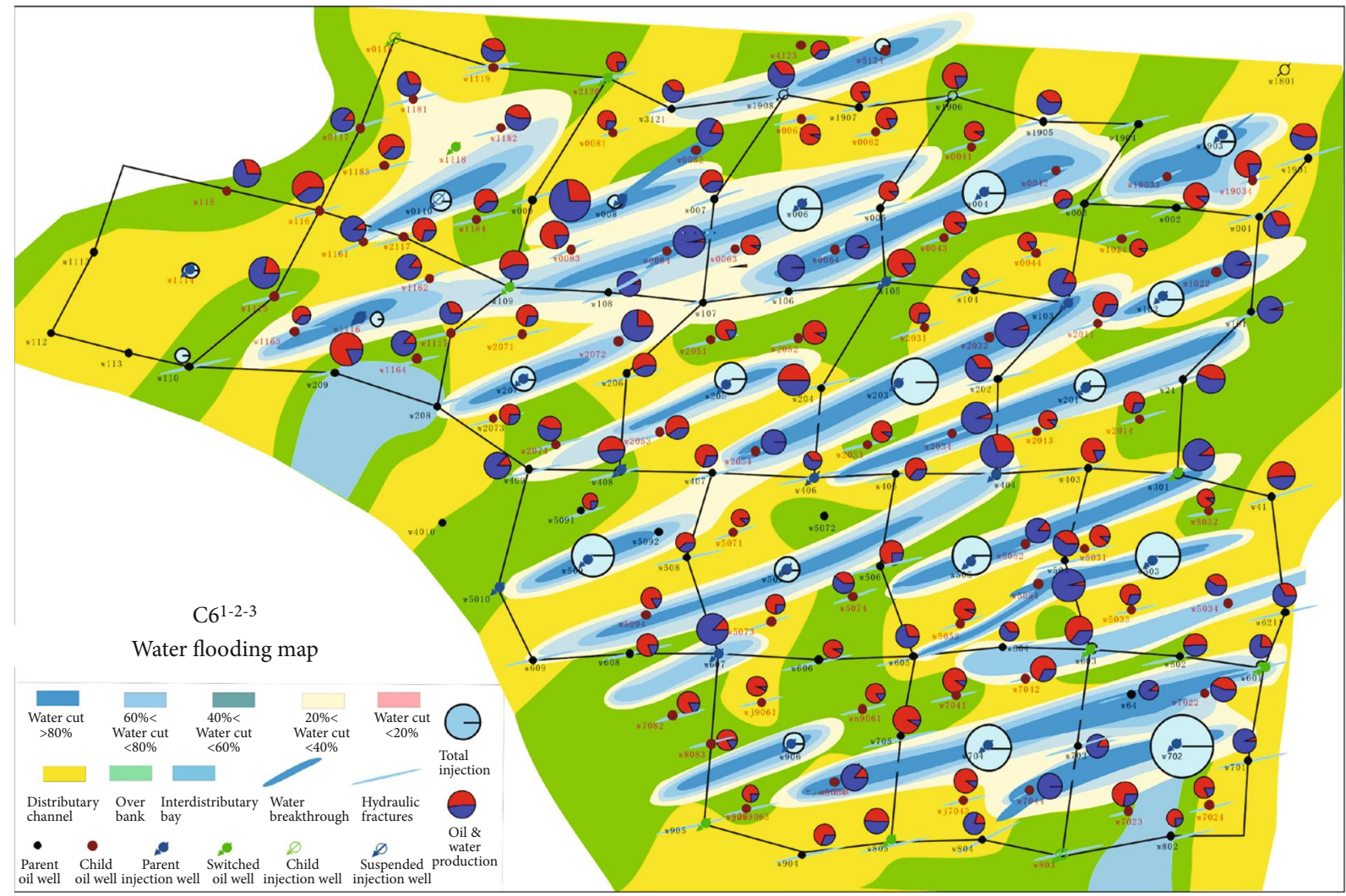

FIgURE 12: The waterflooded state within the $\mathrm{C}^{1-2-3}$ sand layer based on the saturation model.

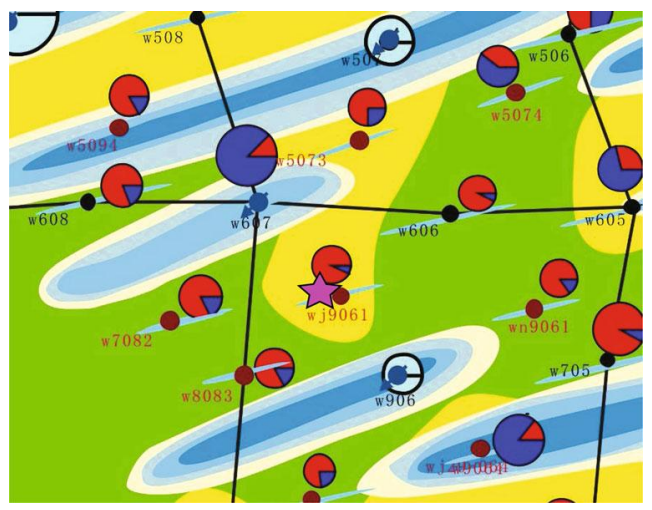

(a)

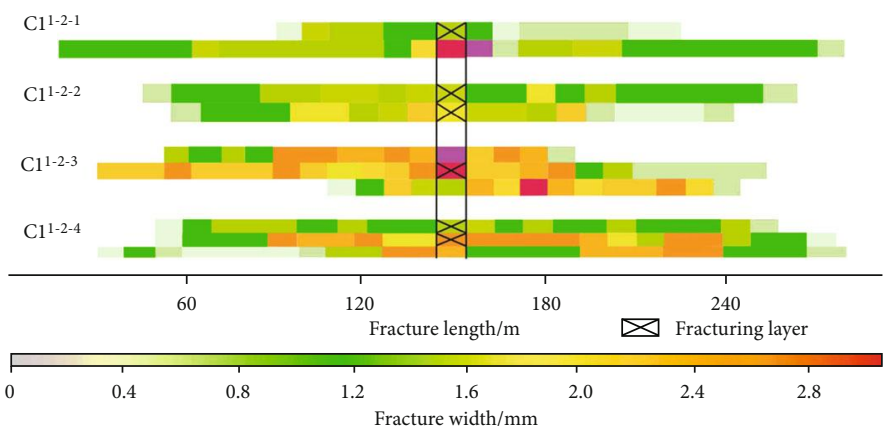

(b)

FIGURE 13: (a) The waterflooded state in the vicinity of well wj9061 in the $\mathrm{C} 6^{1-2-3}$ layer. (b) The newly simulated results of hydraulic fracture propagation in well wj9061 after the refracturing operations for four sand layers.

restrained by the distribution of both microfacies and fractures via the geostatistical method [23].

Figure 8 shows the 3D geological model for different properties within the $\mathrm{C}^{1-2-3}$ sand layer. The grid size of $x$, $y$, and $z$ in the model is set with $5 \mathrm{~m} \times 5 \mathrm{~m} \times 0.1 \mathrm{~m}$. The grid resolution meets the requirement of middle-late oilfield development for the sand layers. The microfacies model is in good agreement with the results of microfacies analysis (Figure 8(a)). Three colors in the map denote the distributary channel (orange), the overbank sand (green), and the interdistributary bay (blue). The porosity model and permeability model, constrained by the facies distribution, are shown in Figures 8(b) and 8(c). It is found that the average porosity and permeability of the distributary channel, overbank, and interdistributary bay are $15.8 \%$ and $5.1 \times 10^{-3} \mu \mathrm{m}^{2}, 13.6 \%$ and $2.58 \times 10^{-3} \mu \mathrm{m}^{2}$, and $9.2 \%$ and $0.7 \times 10^{-3} \mu \mathrm{m}^{2}$, respectively, in the $\mathrm{C}^{1-2-3}$ layer, consistent with the previous statistics (Table 2). The Young's modulus and the Poisson's ratio are averaged to be $44.1 \mathrm{GPa}$ and 0.245 , respectively (Figures 8(e) and 8(f)). The water saturation model conforms to the pattern of combined fracture networks (Figure 10). The water breakthrough follows the direction of NE $67^{\circ}$, also 
TABLE 4: The comparison of production performance before and after the refracturing operations.

\begin{tabular}{|c|c|c|c|c|c|c|c|}
\hline \multirow[b]{2}{*}{ Well } & \multirow{2}{*}{$\begin{array}{l}\text { Sand layer for reperforation and } \\
\text { fracturing }\end{array}$} & \multicolumn{3}{|c|}{ Before treatments } & \multicolumn{3}{|c|}{ After treatments } \\
\hline & & $\begin{array}{l}\text { Fluids production } \\
\qquad \mathrm{m}^{3} / \mathrm{d}\end{array}$ & $\begin{array}{c}\text { Oil } \\
\text { production } t / d\end{array}$ & $\begin{array}{l}\text { Water } \\
\text { cut } \%\end{array}$ & $\begin{array}{l}\text { Fluids production } \\
\qquad \mathrm{m}^{3} / \mathrm{d}\end{array}$ & $\begin{array}{c}\text { Oil } \\
\text { production } \mathrm{t} / \mathrm{d}\end{array}$ & $\begin{array}{l}\text { Water } \\
\text { cut } \%\end{array}$ \\
\hline w47 & $\mathrm{C} 6^{1-2-3}$ & 1.32 & 0.39 & 65.9 & 3.11 & 0.95 & 63.7 \\
\hline wj5071 & $\mathrm{C} 6^{1-2-4}$ & 0.52 & 0.39 & 12.5 & 3.89 & 2.7 & 17.4 \\
\hline w2073 & $\mathrm{C} 6^{1-2-3}$ & 1.18 & 0.49 & 50.6 & 7.25 & 2.62 & 56.9 \\
\hline w8083 & $\mathrm{C} 6^{1-2-3}+\mathrm{C} 6^{1-2-4}$ & 1.08 & 0.82 & 9.6 & 5.51 & 3.88 & 16.2 \\
\hline w9063 & $\mathrm{C} 6^{1-2-1}$ & 0.97 & 0.52 & 36.2 & 6.25 & 2.35 & 55.2 \\
\hline wj9061 & $\mathrm{C} 6^{1-2-3}$ & 1.35 & 0.97 & 14.3 & 3.48 & 2.49 & 14.8 \\
\hline w2074 & $C 6^{1-2-1}$ & 2.42 & 1.13 & 44 & 4.4 & 1.23 & 66.8 \\
\hline w3012 & $\mathrm{C} 6^{1-2-1}$ & 4.68 & 0.16 & 95.9 & 4.82 & 1.23 & 72.9 \\
\hline
\end{tabular}

controlled by the spatial distribution of fracture networks (Figure 8(d)).

\subsubsection{Single Sand Layer-Based Remaining Oil Development.} Based on the waterflooded state in coring wells (Figure 7), combined hydraulic-natural fracture networks (Figure 11), and the water saturation distribution in the geological model (Figure $8(\mathrm{~d})$ ), the spatial waterflooded state is determined within the sand layer, as shown in Figure 12. It is found that the water saturation gradually decreases in the direction perpendicular to the water breakthrough line. In addition, the remaining oil is mainly distributed between the water breakthrough lines, with surrounding water saturation lower than $40 \%$. Therefore, the corresponding measures of reperforation and refracturing could be conducted to tap the remaining oil in the sand layer for particular wells.

Figure 13(a) shows the waterflooded state in the vicinity of the well w9061 in the $\mathrm{C}^{1-2-3}$ layer. It is worth noting that the remaining oil possibly distributed between the water breakthrough lines of injection wells w607 and w906. The distribution of the remaining oil is attributed to the existence of the muddy or calcareous interlayers between the $\mathrm{C} 6^{1-2-2}$ and $\mathrm{C6}^{1-2-3}$ layer, which prevent hydraulic fractures from connecting both layers after performing the integrated fracturing operations (Figure 9). Hence, the refracturing operations in 2014 were performed to tap the remaining oil in the four single layers for the well wj9061. The newly simulated results of hydraulic fractures after the refracturing operations are shown in Figure 13(b). It is noted that the hydraulic fractures in the $\mathrm{C}^{1-2-3}$ and $\mathrm{C}^{1-2-4}$ layers propagate more distance than before (Figure 9). Accordingly, the oil production of well wj9061 increased from the $0.97 \mathrm{t} / \mathrm{d}$ to $2.49 \mathrm{t} / \mathrm{d}$, indicating that the remaining oil in the single layers was better tapped after the refracturing operations.

Similarly, the refracturing operations were applied to the other seven wells in the study area to tap the remaining oil of particular sand layers. Table 4 shows the comparison of well production performance before and after the refracturing operations. It is worth noting that the average oil production for eight wells increased from $0.61 \mathrm{t} / \mathrm{d}$ to $2.18 \mathrm{t} / \mathrm{d}$. Simultaneously, the water cut increased slightly from $41.1 \%$ to about $45.5 \%$ on average $[4,5]$. This performance indicates that the remaining oil within the individual sand layer is well devel- oped via the refracturing treatments, which provides insights for further development of likewise tight sandstone reservoirs.

\section{Conclusions}

An integrated approach is proposed to tap the remaining oil in the individual sand layer during the late-stage development of tight sandstone reservoirs. A case study is utilized to demonstrate the effective applicability of this integrated method.

(1) Six sand layers could be divided and correlated within the $\mathrm{C}^{1}$ oil layers. These sand layers have a variety of physical and mechanical properties, leading to the asymmetric distribution of hydraulic fractures. The subaqueous distributary channel is the dominant microfacies in the area. The spatial difference of sand bodies conforms to the features of the multiperiod superimposed channel in the sedimentary environment of fan delta front

(2) The preexisting natural fractures generated from the tectonic movement in the Yanshan and Xishan period of Mesozoic, with a dominant northeast direction of 67 degrees. The full length of hydraulic fractures in all fractured wells range from $102 \mathrm{~m}$ to $205 \mathrm{~m}$. Hydraulic fractures propagate until connect with the preexisting natural fractures and thus generate the combined fracture networks. The water breakthrough pattern in each single layer is primarily ascribed to the spatial distribution of the hydraulicnatural fracture networks and sedimentary microfacies

(3) The refracturing operations based on the remaining oil distribution in single sand layer show effective field applications. The average oil production of related wells increases from $0.61 \mathrm{t} / \mathrm{d}$ to $2.18 \mathrm{t} / \mathrm{d}$. The practical development strategy of field case would solve the problem of uneven profile development and improve the ultimate oil recovery, which provided insights for further development of likewise tight sandstone reservoirs 


\section{Data Availability}

All data included in this study are available upon request by contact with the corresponding author.

\section{Conflicts of Interest}

The authors declare no conflict of interest.

\section{Acknowledgments}

We gratefully acknowledge the Canada First Research Excellence Fund for the financial support.

\section{References}

[1] Y. Wang, X. Song, J. Li, G. Hui, P. Liu, and X. Wang, "Heterogeneity on dynamic fracture, internal configuration of compound sand body and significance to the development of ultra-low permeability reservoir in Erdos Basin," Journal of Northwest University (Natural Science Edition), vol. 48, no. 1, pp. 123-131, 2018.

[2] Y. Wang, X. Song, C. Tian et al., "Dynamic fractures are an emerging new development geological attribute in waterflooding development of ultra-low permeability reservoirs," Petroleum Exploration and Development, vol. 42, no. 2, pp. 222-228, 2015.

[3] J. Li, X. Song, Y. Wang, and G. Hui, "Configuration delineation of thick sandbody within ultra-low permeability reservoir, Wangyaolaoqu, Ansai oilfield," Geological Science and Technology Information, vol. 33, no. 1, pp. 129-136, 2014.

[4] D. Zhu, M. Pan, Y. Dang, Z. Zhu, P. Liu, and Y. Shi, "Characterization and fracturing stimulation on single sand body of tight sandstone oil reservoir in Ansai oilfield," Acta Scientiarum Naturalium Universitatis Pekinensis, vol. 52, no. 3, pp. 457-466, 2016.

[5] P. Liu, Z. Zhang, X. Wang, M. Pan, and Y. Shi, "Revelation on remaining oil and full-length hydraulic simulation of single sand bodies based on 3D models in low permeability heterogeneous reservoirs," Journal of China University of Petroleum (Edition of Natural Science), vol. 41, no. 3, pp. 56-64, 2017.

[6] L. G. John, "Recent advances in hydraulic fracturing," $S P E$ Monograph Series, vol. 21, 1990.

[7] C. R. Fast, G. B. Holman, and R. J. Cavlin, "The application of MHF to the tight muddy "J" formation Wattenberg field, Colorado," Annual Technical Meeting. Calgary: Petroleum Society of Canada, vol. PETSOC-7612, 1976.

[8] Z. Rahim and S. A. Holditch, "The effects of mechanical properties and selection of completion interval upon the created and propped fracture dimensions in layered reservoirs," Journal of Petroleum Science and Engineering, vol. 13, no. 1, pp. 29-45, 1995.

[9] M. Abdideh and A. Ahmadifar, "Prediction of geomechanical modeling and selection of suitable layer for hydraulic fracturing operation in oil reservoir (South West of Iran)," European Journal of Environmental and Civil Engineering, vol. 17, no. 10, pp. 968-981, 2013.

[10] Q. Wen, C. Pu, and Z. Qu, “Optimization design of non-Darcy percolation fracturing in low permeability and extra-low permeability reservoirs," Petroleum Geology and Recovery Efficiency, vol. 16, no. 6, pp. 102-104, 2009.
[11] Z. Wang and Y. Sun, "A study of the factors affecting the results of repeated hydrofracturing in wells in a tight reservoir," Acta Petrolei Sinica, vol. 11, no. 3, pp. 50-59, 1990.

[12] D. Weng, T. Jiang, Y. Xu, K. Shen, H. Zhang, and X. Lv, "Study on well and layer selection for refracturing in Ansai Oilfield," Oil Drilling \& Production Technology, vol. 30, no. 4, pp. 5862, 2008.

[13] Q. Zhang, Z. Bao, X. Song, and J. Sun, "Hierarchical division and origin of single sand bodies in Fuyu oil layer, Fuyu Oilfield," Petroleum Exploration and Development, vol. 35, no. 2, pp. 157-163, 2008.

[14] Y. Meng, J. Gao, J. Niu, H. Sun, and Y. Wang, "Controls of the fan-delta sedimentary microfacies on the diageneses in the south of western Liaohe Depression, Bohai Bay Basin," Petroleum Exploration and Development, vol. 33, no. 1, pp. 36-39, 2006.

[15] H. Su, Z. Lei, D. Zhang et al., "Dynamic and static comprehensive prediction m7ethod of natural fractures in fractured oil reservoirs: a case study of Triassic Chang 63 reservoirs in Huaqing Oilfield, Ordos Basin, NW China," Petroleum Exploration and Development, vol. 44, no. 6, pp. 919-929, 2017.

[16] S. Liu, H. He, Q. Zhao, and D. Zhou, "Staggered extension laws of hydraulic fracture and natural fracture," Acta Petrolei Sinica, vol. 39, no. 3, pp. 320-326, 2018.

[17] L. Zeng, "Formation and distribution of fractures in low permeability sandstone reservoirs," Beijing Science Press, Beijing, 2008.

[18] L. Zhang, "Characteristics of reservoir fracture and the analysis of stress field in Shaanxi-Gansu-Ningxia basin," Geological Science and Technology Information, vol. 22, no. 2, pp. 21-24, 2003.

[19] W. Ronald, L. Don, L. Laurence, E. Thomas, and E. David, "Application of structural interpretation and simultaneous inversion to reservoir characterization of the Duvernay Formation, Fox Creek, Alberta, Canada," The Leading Edge, vol. 38, no. 2, pp. 151-160, 2019.

[20] X. Zhou, W. Meng, and L. Gan, "Simulation of stress field distribution in fractured reservoirs of horizontal wells," Global Geology, vol. 36, no. 3, pp. 924-930, 2017.

[21] B. Guan, J. Guo, Y. Yang, H. Zhao, and J. Zheng, "Methods of fracture prediction in oil \& gas reservoirs and their development trend," Special Oil \& Gas Reservoirs, vol. 21, no. 1, pp. 12-17, 2014.

[22] J. Sun, D. Liu, W. Zhang, and J. Tang, "Using production performance data to determine fracture distribution of low permeability reservoir," Petroleum Geology \& Oilfield Development in Daqing, vol. 30, no. 1, pp. 95-98, 2011.

[23] Y. Nie, J. Tian, S. Wei, and L. Sun, "Difficulties and treatments in three-dimensional geological modelling of fractural reservoirs," Petroleum Geology and Recovery Efficiency, vol. 20, no. 2, pp. 39-41, 2013. 